\title{
Sporcularda ayak stres kırıkları
}

\section{Stress fractures of the foot and ankle in athletes}

\author{
Umut Yavuz¹, Namık Kemal Özkan² \\ ${ }^{1}$ İstanbul Aydın Üniversitesi Tıp Fakültesi, Ortopedi ve Travmatoloji Anabilim Dalı, İstanbul \\ ${ }^{2}$ Özel Maltepe Ersoy Hastanesi, Ortopedi ve Travmatoloji Kliniği, İstanbul
}

\begin{abstract}
Ayak ve ayak bileği çevresinde görülen stres kırıkları, sporcularda sıklıkla karşılaşılan ve spordan uzak kalmaya neden olabilecek önemli bir sakatlık nedenidir. Çoğunlukla sinsi başlangıçlı bir problemdir ve bu patolojiden şüphelenmek için ayrıntılı bir klinik değerlendirme yapılmalıdır. Stres kırığı şüphesi olanlarda radyografik çalışmalar sıklıkla geç pozitif olduğundan erken tanı için daha sensitif yöntemler olan sintigrafi ve manyetik rezonans (MR) ile değerlendirme yapılır. Ayak ve ayak bileği çevresi stres kırıkları iyileşme potansiyeli ve cerrahi tedavi gereksinimi açısından yüksek ve düşük riskli stres kırıkları olarak iki gruba ayrılır. Düşük riskli kırığı olan sporcular sıklıkla yük vermeden kesme ve istirahat ile komplikasyonsuz iyileşir ve de spora daha erken dönerler. Yüksek riskli grupta ise tam kırık riski yüksektir, spora dönüş süresi sıklıkla daha uzundur ve cerrahi tedavi gerekebilmektedir. Tedavi genelde kırığın yeri ve türüne göre değişkenlik göstermekle birlikte, D vitamini, kemik stimülatörleri, kalsitonin, bifosfonat ve ESWT (extracorporeal shock wave therapy) gibi diğer cerrahi dışı yöntemlerinde erken iyileşme için tedaviye eklenmesi şeklinde, literatürde çalışmalar mevcuttur.
\end{abstract}

Anahtar sözcülkler: sporcu; stres kırığı; ayak; ayak bileği
Stress fractures observed in foot and ankle are frequently seen in sportsmen, leading to disability that may keep them away from sports. A detailed clinical evaluation is necessary to suspect the presence of the stress fracture because its onset is mainly insidious. For early diagnosis, scintigraphy and magnetic resonance imaging (MRI) are preferred because radiographic studies are frequently positive in the late period of the stress fracture. Stress fractures in the foot and ankle are divided into two subgroups as low and high risk based on their cure potential, and necessity of the surgical intervention. Prevention of loading on the region of fracture and rest are main treatment options without any complication for the low-risk group. On the other hand, the possibility of complete fracture is higher in the high-risk group, and in comparison with the low-risk group, subjects in this group have a lower chance for improvement without surgery, and need to more time to get back to sports. Although the type of treatment including surgery versus non-surgery approaches or both depends on the location and the type of fracture, recent data emphasize that the other non-surgery options such as vitamin D, bone stimulants, calcitonin, bisphosphonates, and ESWT (extracorporeal shock wave therapy) are essential for improvement at the early period.

Key words: athlete; stress fracture; foot; ankle

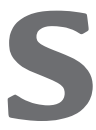
porcularda ayak ve ayak bileği stres kırıkları, seviye ve yaş gözetmeksizin sık gözlenen bir problemdir ve yapılan spora göre \%1-15 arası görülme oranı vardır. ${ }^{[1-3]}$ Literatürdeki çoğu çalışma askeri personeller ile ilgili olsa da ${ }^{[4]}$, sporcularda da stres kırıkları sıktır ve önemli bir sakatık nedenidir. Stres kırıkları en sık alt ekstremitede ve özellikle ayak ve ayak bileği çevresi (\%34) ve tibiada (\%49) gözlenir. ${ }^{[2,5,6]} \mathrm{Her}$ sporcuda görülebilmekle birlikte, daha sıklıkla koşucular ve zıplamalı spor yapan sporcularda gözlenir ve kadınlarda görülme sıklığı daha fazladır. ${ }^{[2,7-10]}$

\section{PATOGENEZ VE NEDENLERI}

Stres kırıkları, akut kırıklarının aksine, tek bir maksimum yüklenme ile değil tekrarlayıcı ve maksimum olmayan yüklenmeler ile oluşur. ${ }^{[2,8]}$ Bununla birlikte, kemik içindeki yapım ve yıkım dengesizliği de kırığın oluşması için uygun ortam oluşturur ve yüklenme sonrası mikrokırıklara neden olur.

Kırık oluşmadan önceki aşama stres reaksiyonu aşamasıdır ve semptomlar oluşmaya başlamıştır. MR'de kırık olmaksızın ödem ve sintigrafide ise tutulum ile tanı

- İletişim adresi: Dr. Umut Yavuz, İstanbul Aydın Üniversitesi Tıp Fakültesi, Ortopedi ve Travmatoloji Anabilim Dalı, Sağlık Uygulama ve Araştırma Hastanesi, Küçükçekmece, İstanbul Tel: 0532 - 7282190 e-posta: umut78@yahoo.com

- Geliș tarihi: 1 Ocak 2018 Kabul tarihi: 1 Ocak 2018 
konulur. Tedavi uygulanmaksızın stres etkeni ortadan kalkmaz ise stres kırığı oluşur. Stres kırığı oluşmasında iç ve dış etkenler tanımlanmıştır ve bunlar çoğunlukla birliktedir. ${ }^{[3,11-13]}$ Hastanın anatomisi, yaş, cinsiyet, ayaktaki yapısal bozukluklar, kemik kalitesinde kayıp, kanlanma bozuklukları ve özellikle kadın sporcularda gözlenen hormonal bozukluklar, iç etkenlere örnek olarak sayılabilir. Aktivite tipi ve yoğunluğu, antrenman yoğunluğu, spor yapılan zemin, kullanılan teknik ve ekipman, beslenme tipi dış etkenlerdir. Kas yorgunluğu ve özellikle kadınlarda görülen kas kitlesi azlığı, kemiğe yüklenen strese karşı oluşması gereken kas korumasının daha az olmasına neden olmaktadır. ${ }^{[12]}$

Kadın sporcularda stres kırığı, anatomik yapı, hormonal dengesizlik ve kas gücü gibi nedenlere bağlı olarak daha fazla gözlenir. Bacaktaki genu valgum'a sekonder olarak $\mathrm{Q}$ açısının fazla olması ve buna sekonder olarak artmış ayak pronasyonu, anatomik bir nedendir. ${ }^{[12,14]}$ Ayrıca, kadın sporcularda yeme hastalığı, amenore ve osteoporoz ile seyreden "kadın atlet üçlemesi" diğer bir kolaylaştırıcı etkendir. Özellikle yüksek dayanıklılık sporları, artistik patinaj, koşucular ve jimnastikçilerde sık gözlenir. Diğer bir önemli hormonal neden ise, her iki cinste seks hormonlarının sıkı antrenman dönemleri sonrasında düşmesi nedeniyle, osteoklastların artması, osteoblastların azalması ve bunlara bağlı olarak kemik mineral yoğunluğunun azalıp kemiklerin kırığa yatkın hale gelmesidir. ${ }^{[15-17]}$

\section{SINIFLAMA, TANI VE TEDAVi}

Stres kırıkları bulunduğu yer, iyileşme potansiyeli, kaynamama riski ve cerrahi tedavi gereksinimi gibi farklı özellikler göz önüne alınarak, düşük riskli ve yüksek riskli iki ana kategoriye ayrılmıştır (Tablo 1). Yüksek riskli stres kırıkları, tam kırık oluşma riski veya kaynamama riski daha fazla olan kırıklardır. Ayrıca, iyileşme süreci daha uzundur ve spora dönüş gecikir. Medial malleol, talus, navikula, proksimal 5. metatars ve sesamoid kırıkları bu gruptandır. Düşük riskli kırıklar ise genellikle istirahat ve yükten kesme ile komplikasyonsuz tedavi edilir ve spora dönüş daha kısa sürede olur. Kalkaneus, fibula, metatars cisim kırıkları, küboid ve kuneiformlardaki kırıklar bu gruba girer. ${ }^{[2,3,8,18]}$

Hastalar, sıklıkla uzun süredir devam eden, zamanla kendini gösteren ilerleyici bir ağrıdan şikayet ederler. Bazen ağrıya şişlik de eşlik edebilir. Şikayetlerin süresi ve miktarı, antrenman özellikleri, sporcunun özellikleri, ekipman ve zemine göre değişkenlik gösterir. ${ }^{[3,6,7,11,13,19-21]}$ Hastanın şikayetleri sorgulanırken; yaş, cinsiyet, beslenme şekli, antrenman özellikleri, ekipman ve zemin özellikleri ve bayanlarda menstrual siklus sorgulanmalıdır. ${ }^{[3,7,8,14,21]}$ Klinik muayene sırasında; topallama varlığı, şişlik, deri değişikleri, ağrının yayılım alanı ve palpasyonla ağrılı noktanın yeri dikkatlice değerlendirilmelidir. Bunun yanında, hastanın alt ekstremite anatomisi de değerlendirilerek stres kırığına zemin hazırlayacak patolojiler (kavus veya planus ayak, genu valgum) atlanmamalıdır.

Klinik şüphe oluşan sporcularda tanıyı kesinleştirmek için radyolojik tetkikler kullanılır. Geç dönemde radyografiler yeterli olurken, erken dönemde kallus görülemeyeceği için kemik sintigrafisi, manyetik rezonans (MR) görüntüleme ve bilgisayarlı tomografi (BT) gibi daha ileri radyolojik yöntemler kullanılır. ${ }^{[2,22,23]}$ Radyografik tetkik minimum iki haftanın sonunda bulgu verir ve rezorpsiyon, skleroz veya kallus gözlenebilir. Radyonükleid kemik sintigrafisinde Teknesyum-99 kullanılır ve olayın başlangıcından $48-72$ saat sonra her üç fazda da tutulum olması ile tanı konulur. Çok yüksek oranda sensitivite oranına sahipken spesifisite oranı düşüktür ve yanlış pozitif (enfeksiyon veya malignite) verebilir. Zamanla, erken tanı açısından MR, sintigrafinin yerini almış ve hem spesifisite hem de sensitivite açısından üstünlük sağlaması nedeniyle altın standart tanı yöntemi olarak tercih edilmektedir. ${ }^{[24-26]}$ BT ise, stres reaksiyonunu göstermemekle birlikte, skleroz

Tablo 1. Ayak ve ayak bileği çevresi stres kırıklarının genel özellikleri

\begin{tabular}{|c|c|c|}
\hline & Kırık yeri & Özellikleri \\
\hline Yüksek riskli kırıklar & $\begin{array}{l}\text { Medial malleol } \\
\text { Talus } \\
\text { Navikula } \\
\text { Sesamoid } \\
\text { 5. metatars bazisi }\end{array}$ & $\begin{array}{l}\text { * İyileşme süresi ve spora dönüş uzundur. } \\
\text { * Kaynamama riski vardır. } \\
\text { * Cerrahi tedavi gerekebilir. }\end{array}$ \\
\hline Düşük riskli kırıklar & $\begin{array}{l}\text { Fibula/lateral malleol } \\
\text { Kalkaneus } \\
\text { Küboid } \\
\text { Kuneiform } \\
\text { Metatars cisim }\end{array}$ & $\begin{array}{l}\text { * İyileşme süresi ve spora dönüş kısadır. } \\
\text { * İstirahat ve yükten kesme ile sorunsuz iyileşir. } \\
\text { * Cerrahi tedavi gerekmez. }\end{array}$ \\
\hline
\end{tabular}



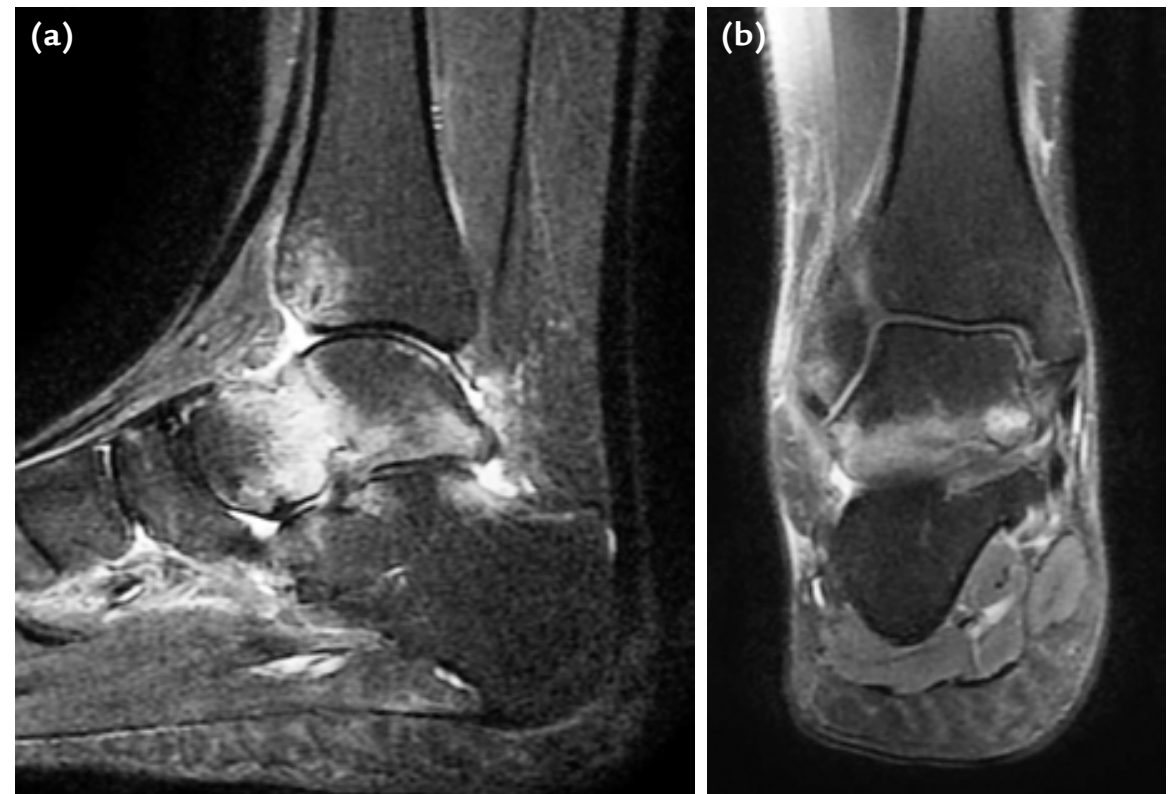

Şekil 1. a, b. Talus orta-anterior kısımda görülen stres kırığı: sagittal kesit (a); koronal kesit (b).

ile birlikte komplet veya inkomplet kırıkları göstermek için kullanılabilir. ${ }^{[22,26]}$ Ayrıca, iyileşmenin takibi açısından daha üstün bir yöntemdir.

\section{YÜKSEK RISKLI KIRIKLAR}

\section{Medial Malleol Stres Kırı̆ı̆}

Bu kırıklar sık görülmemekle birlikte, literatürde \%4'e kadar bildiren yayınlar mevcuttur. ${ }^{[9,27]}$ Sıklıkla koşucular, zıplamalı ve tekme kullanılan sporlarda tekrarlayıcı rotasyonel yüklenme sonucu oluştuğu düşünülmektedir. Diğer bir neden olarak, anterior sıkışma yapacak osteofit gibi lezyonların da olduğu gösterilmiştir. ${ }^{[28-30]}$ Klinik değerlendirmede; aktivite sırasında ağrı, malleol üzerinde ve ayak bileğinin önünde hassasiyet ve şişlik gözlenir. Ayırıcı tanıda PTT (posterior tibial tendon) yetmezliği, artrit, tarsal tünel sendromu ve deltoid bağ yaralanması sayılabilir. Stres kırığından şüphelenilen hastalarda öncelikle grafi çektirilir. Grafide plafonddan başlayan vertikal radyolusen bir hat görülmesi tanı koydurucudur. Grafide patoloji gözlenmez ise (\%70 civarı), MR ve sintigrafi planlanmalıdır. MR, spesifisitesinin yüksek olması, invaziv olmaması ve çok planlı görüntü alınabilmesi açısından daha üstündür ve daha çok tercih edilir.

Tedaviye aktivite modifikasyonu ve kısa dönem immobilizasyon ile başlanır. Şişlik ve hassasiyetin gerileme durumuna göre, hasta kontrollü şekilde spora başlatılır. Bu tedaviye rağmen şikayetleri devam eden veya grafide vertikal kırık hattı gözlenen hastalarda cerrahi tedavi seçilir. ${ }^{[28,30-33]}$ Cerrahi tedavide, açık ya da kapalı $4 \mathrm{~mm}$ kanüle vida tedavisi veya sadece drilleme tedavileri uygulanmaktadır. ${ }^{[28,29,32,33]}$ Cerrahi sonrası ilk üç hafta yük verilmez ve sonrasında aşamaIı olarak spora başlanır. Yapılan çalışmalarda tedavi konusunda fikir birliği olmasa da, cerrahi tedavi uygulanan hastaların spora dönüşünün daha kısa olduğu söylenmektedir. ${ }^{[30,34]}$

\section{Talus Stres Kırı̆gı}

Çok ender olan talus stres kırığı, ilk kez 1965 yılında tanımlanmıştır ve literatürde olgu sunumu şeklinde örnekler görülmektedir. ${ }^{[35-37]}$ Tekrarlayıcı aksiyel yüklenme yapan sporcular ve askeri personel, bu tarz kırık oluşmasına eğilimlidir. Hasta kliniğe, topallama ve ayak bileği ve ayak tabanına vuran ağrı ile başvurur. Palpasyonla, talus ön kısmına uyan bölgede hassasiyet ve şişlik gözlenebilir. Hastaların yarısından fazlasında kırık, talus baş kısmında gözlenmekle birlikte, sırasıyla cisim ve arka kısımlarda da gözlenebilmektedir. ${ }^{[37,38]}$ Nedenler ve ağrının yayılımı, bulunduğu yere göre değişebilir. Baş kısmı kırıkları navikula stres yaralanması; cisim kırıkları kalkaneus yaralanması ve arka kısım kırıkları da posterior sıkışma veya semptomatik os trigonum ile birliktelik gösterebilir. ${ }^{[37]}$ Bununla birlikte, lateral kısım kırıkları da gözlenebilir ve bunun da lateral kısmın kalkaneus lateral çıkıntısının talus posterolateral kısmı üzerine sıkışma yapması sonucu oluştuğu söylenmektedir. ${ }^{[36,39,40]}$ Tanı için radyografi çoğu zaman yetersizdir ve MR çoğunlukla tanı koydurucudur (Şekil 1). ${ }^{[14,37]}$ Tedavide belli bir standart yöntem 
olmamakla birlikte, çoğu zaman istirahat ve yükten kesme gibi cerrahi dışı yöntemler ile 8-12 haftada iyileşme sağlanır. ${ }^{[36,37]}$ Avasküler nekroz bildiren çalışma yoktur, ancak birkaç hastada inatçı ağrı ile birlikte dejenerasyon bildirilmiştir. ${ }^{[37]}$

\section{Navikula Stres Kırı̆ı}

$\mathrm{Bu}$ kemik kırıkları sık görülmez, ancak çoğunlukla sürat koşucuları ve zıplama gerektiren sporları yapanlarda gözlenir ve kaynamama potansiyeli yüksek kırıklardan biridir. ${ }^{[2,3,41]}$ Ağrı genellikle ayak dorsal yüzde ve ayak medial kısmında yoğunlaşır. ${ }^{[41]}$ "N-nokta hassasiyeti" olarak da adlandırılan, navikula dorsal yüzde hassasiyet gözlenir. ${ }^{[2,3,42]}$

Navikula kanlanması, lateralde dorsalis pedisten gelen dal ve medialde ise tibialis posteriordan gelen dal ile olur ve orta kısım bu damarlardan gelen kanın yayılması ile beslenir. ${ }^{[43]} \mathrm{Bu}$ nedenle, orta kısmın kanlanması hem stres kırığına daha meyilli olma hem de daha yavaş iyileşme nedenidir. Bunun dışında, navikula kemiğinin talus ve $1-2$. metatarslar arasında makaslama gücüne maruz kalması ${ }^{[4]}$, uzun ikinci metatars, kavus ayak, metatarsus adduktus, talar kırılma ve sınırlı eklem hareketleri, diğer nedenler arasındadır. ${ }^{[3,44,45]}$

Navikula stres kırı̆ıında, kırık hattı proksimal dorsalden plantar distale doğru yönlenir. ${ }^{[44,46]}$ Radyolojik olarak öncelikle radyografi çekilir ve eğer negatif ise $M R$ veya sintigrafi istenir. Bu kırıklarda bu iki yöntemin BT'ye üstünlüğü gösterilmemiştir. ${ }^{[46,47]}$

Tedaviye, öncelikle yükten kesme ve kısa bacak alçı tedavisi olarak başlanır ${ }^{[3,42,44,48]}$ ve sıklıkla olumlu sonuç bildirilmiştir. Tedaviye 6-8 hafta devam edilmesi önerilir. Bununla birlikte, başlangıçta cerrahi tedavi uygulananlarda spora dönüşün daha erken olduğu ileri sürülse de, yapılan çalışmalarda sonuçlar arasında belirgin fark gösterilememiştir. ${ }^{[41,48-50]}$ Literatüre baktığımızda, cerrahi tedavi genellikle deplase kırıklar, sklerotik değişiklik olan deplase olmayan kırıklar, konservatif tedavinin yeterli olmadığı veya tolere edemeyen hastalar için önerilmiştir. ${ }^{[44,51,52]}$ iki adet 4,0 mm kanüle vida, sık uygulanan tekniktir ve sonrasında N-nokta hassasiyeti bitene kadar, yük vermeden takip edilir. Defektli veya skleroz olan kırıklarda otogreft kullanılabilmektedir.

\section{Proksimal Beşinci Metatars Stres Kırığı}

Bu bölge stres kırıkları, akut kırıktan hem klinik hem de radyolojik olarak farklılık gösterir. Klinik şikayet süresi yaklaşık 3-6 hafta arasındadır ve ağrı genellikle diyafiz kısmına yayılır. Genellikle zıplamalı sporlarda görülür ve plantar fleksiyon sırasında tekrarlayıcı adduksiyon ve vertikal güç sonrası oluştuğu söylenmektedir. ${ }^{[2,3,53,54]}$

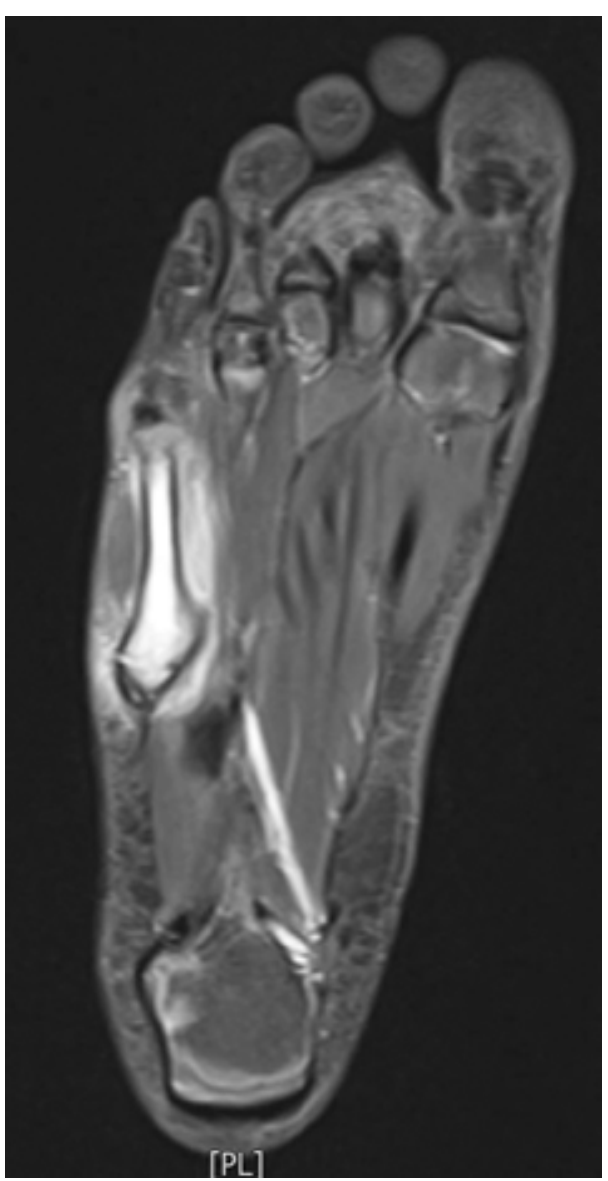

Şekil 2. Beşinci metatars bazisi stres kırığı.

Ayrıca, kavovarus ayak, geniş 5. metatars abduksiyon açısı ve sınırlı ardayak eversiyonu, predispozan faktörler arasında sayılmaktadır. ${ }^{[3,55,56]}$

Hastalar kliniğe genellikle uzun süredir var olan lateral ayak ağrısı, 5. metatars üzerinde hassasiyet ve inversiyon sırasında belirgin ağrı ile başvururlar. Radyografi geç bulgu verir ve tanı erken dönemde MR ile koyulur (Şekil 2). Torg ve ark. ${ }^{[57]}$ klinik ve radyolojik görünüme dayalı olarak bir sınıflama tanımlamışlardır. Tip 1 kırıklarda akut kırık ile birlikte keskin kırık hattı mevcuttur ve intramedüller skleroz yoktur. Tip 2 kırıklarda gecikmiş kaynama ile birlikte periosteal yeni kemik oluşumu ve skleroz mevcuttur. Tip 3 kırıklarda ise genellikle tekrarlayıcı travma öyküsü vardır ve kaynamama, geniş kırık hattı ve medullar kanalın kaybolması gözlenir.

Tedavi, genellikle kırığın aşamasına, aktivite düzeyine ve spora dönme talebine göre planlanır. Tip 1 kırıklar genellikle kısa bacak alçı ve yükten kesme ile tedavi edilir. ${ }^{[57,58]}$ Tip 2 ve 3 kırıklarda genellikle vida ve gergi bandı yöntemi ile cerrahi tedavi önerilmekle birlikte, otogreft kullanımı da hastaya bağlı olarak 
cerrahiye eklenebilmektedir. ${ }^{[53,54,56,57,59]}$ Plantar gap $1 \mathrm{~mm}$ 'den büyük olanlarda kaynama zamanı yüksek olarak bulunmuş ve bu tip kırıklarda ve Tip 3 kırıklarda otogreftleme önerilmiştir. ${ }^{[50,60,61]}$ Cerrahi sonrası ikinci haftada yük verilmiş; ortalama spora dönüş cerrahiye göre değişmekle birlikte, Tip 2 kırıklarda sekiz hafta, Tip 3 kırıklarda ise 12-16 hafta arası olarak gözlenmiştir. [57,60]

\section{Sesamoid Stres Kırığı}

Medial sesamoid kemiği direkt 1. metatars başı altındadır ve bu nedenle daha sıklıkla kırık gözlenir. Dansçılar, basketbolcular ve atlamalı sporları yapanlarda sıktır ve parmakların güçlü dorsifleksiyonu ile ilişkili olduğu düşünülmektedir. ${ }^{[16,62,64]}$ Şişlik, palpasyonla hassasiyet ve güçlü dorsifleksiyonda şiddetlenen ağrı şikayetleri mevcuttur. Ayırıcı tanıda; sesamoidit, gut, akut kırık, sinir tuzaklanması ve artrit sayılabilir. ${ }^{[62]}$

Radyolojik olarak öncelikle her iki ayak radyografisi istenir ve bipartit sesamoid ile ayırım sağlanır. Keskin kenarlı olması ve parçalı olması ile bipartit sesamoidden ayırım sağlanır. Bununla birlikte kesin tanı MR veya BT ile sağlanır. MR ayrıca ayırıcı tanı için de etkin bir tetkik yöntemidir.

Tedavide ilk uygulanacak yöntem; istirahat, yükten kesme, ayakkabı modifikasyonu, ilaç tedavisi veya steroid enjeksiyonudur. ${ }^{[16,62-64]}$ Tedaviye rağmen 8-12 hafta yanıt alınamayan hastalarda; perkütan vidalama, greftleme, kısmi veya total sesamoidektomi uygulanmakta ve \%90'ın üstünde başarı sağlanmaktadır. Bununla birlikte, cerrahi sonrası halluks valgus ve fleksör hallusis longus yaralanması bildirilen komplikasyonlar arasındadır. ${ }^{[7,16,64-66]}$

\section{DÜŞÜK RISKLI KIRIKLAR}

\section{Fibula Stres Kırığı}

Çok nadir bir kırık olsa da, koşucularda sık rastlanmaktadır. ${ }^{6]}$ Fibula boyunca oluşabilmekle birlikte en sık distal 1/3'lük kısımda ve sindesmotik bağların hemen proksimalinde görüldüğü bildirilmiştir. ${ }^{[6]}$ Diğer bir çalışmada ise, en sık yerleşim yerinin lateral malleol tipinin 4-7 cm üzeri olduğu bulunmuştur. ${ }^{[67]}$

Bu bölge stres kırıklarının, tekrarlayıcı aksiyel yüklenme ve ayak bileği fleksörlerinin güçlü kasılmasının kombinasyonu ile oluştuğu düşünülmektedir. Aksiyel yüklenme ile, fibulaya vücut ağırlığının \%2-10 kadarı bir yük biner ve bu, ayak bileği pozisyonuna göre değişkenlik gösterir. ${ }^{[67,68]}$ Ayrıca, kırık oluşumu sporcuya veya antrenman şekline ve yerine göre de değişmektedir.
Hastalar sıklıkla, sinsi başlayan ve spor sırasında artan ayak bileği dış yan ağrısı ve şişlikten şikayetçidirler. Erken dönemde radyografiler sıklıkla bulgu vermez, $M R$ veya sintigrafi planlanır. MR'nin sintigrafiye üstünlüğü, hem spesifisitesinin yüksek olması hem de ayırıcı tanılar olan tendinit, kondral lezyon, peroneal tendon hastalıkları veya lateral kompartman sendromu gibi hastalıkları da gösterebilmesidir.

Cerrahi dışı tedaviler çoğunlukla yeterlidir ve cerrahi tedavi gerektirmez. İstirahat, aktivite modifikasyonu ve bazen de kısa süre yükten kesme sonrası rahatlama sağlanır. Kırık bölgesinde hassasiyet kaybolunca ve radyolojik iyileşme gözlenince spora dönüşe izin verilir. ${ }^{67,68]}$

\section{Kalkaneus Stres Kırığı}

Sıklıkla uzun mesafe koşucularında ve askeri personelde gözlenmekle birlikte, askerler ile ilgili olgu serileri literatürde daha sıktır. ${ }^{[6,69,70]}$ Hastalar kliniğe sıklıkla sinsi başlayan, zamanla artan ve de özellikle de aktivite ile kendini gösteren ağrı ile başvururlar. Şişlik, her zaman olmamakla birlikte gözlenebilir. "Kalkaneal kompresyon testi" sıklıkla pozitiftir. Ayırıcı tanıda; plantar fasiit, Baxter sinir tuzaklanmaSı, Aşil tendiniti, Sever hastalığı ve retrokalkaneal bursit akla getirilmelidir. ${ }^{[3]}$

Hastaların erken dönem çekilen radyografilerinde çoğunlukla bulgu saptanmamakla birlikte, üç haftadan sonra vertikal sklerotik bir hat şeklinde gözlenebilir. Kesin tanı sintigrafi ve MR ile konulabilir, ancak diğer ayırıcı tanıların elenmesi açısından MR daha etkin bir yöntemdir (Şekil 3). Güncel bir çalışmada, MR çekilen hastaların \%56'sında posterior tuberositas seviyesinde kırık gözlenmekle birlikte, kalan hastalarda ön ve orta kısımda kırık görülmüştür. ${ }^{[70]}$ Hastalar, yükten kesme ve istirahat ile yaklaşık sekiz haftada tedavi edilebilir ve spora dönebilirler.

\section{Metatars Cismi Stres Kırığı}

Sıklıkla koşucu ve askerlerde olmakla birlikte, dansçı ve basketbolcularda da gözlenebilmektedir. ${ }^{[6,9,27,71]}$ Sıklıkla 2. ve 3 . metatarslarda gözlenmekle birlikte (Şekil 4) en sık 2. metatars distalinde gözlenir. ${ }^{[63]}$ Sıklıkla yoğun egzersiz ve antrenman yüzeyi değişiklikleri sonrasında gözlendiği belirtilmiştir.

Hastalar çoğunlukla, sinsi başlangıçlı ve yük verince oluşan ön ayak ağrısı, yürümede zorlanma ve bazen de şişlik şikayeti ile başvururlar. Muayenede, N-nokta hassasiyeti, sıkıştırma testinde pozitiflik ve şişlik gözlenebilir. Metatarsalji, enfeksiyon ve Morton nöroma ayırıcı tanılar arasında belirgin olanlardır. 

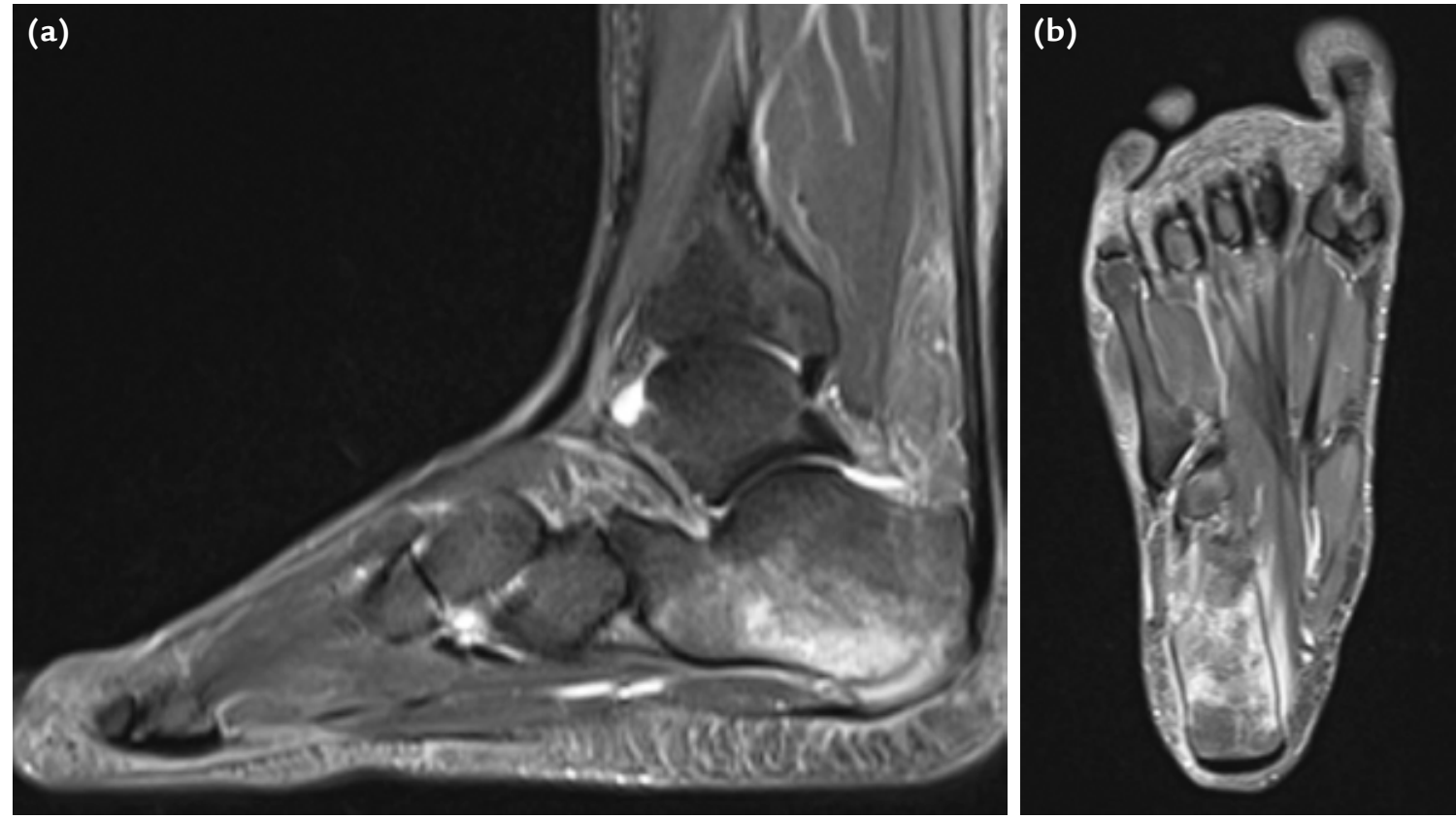

Şekil 3. a, b. Basketbol oyuncusunda görülen kalkaneus stres kırığı: sagittal kesit (a); aksiyel kesit (b).
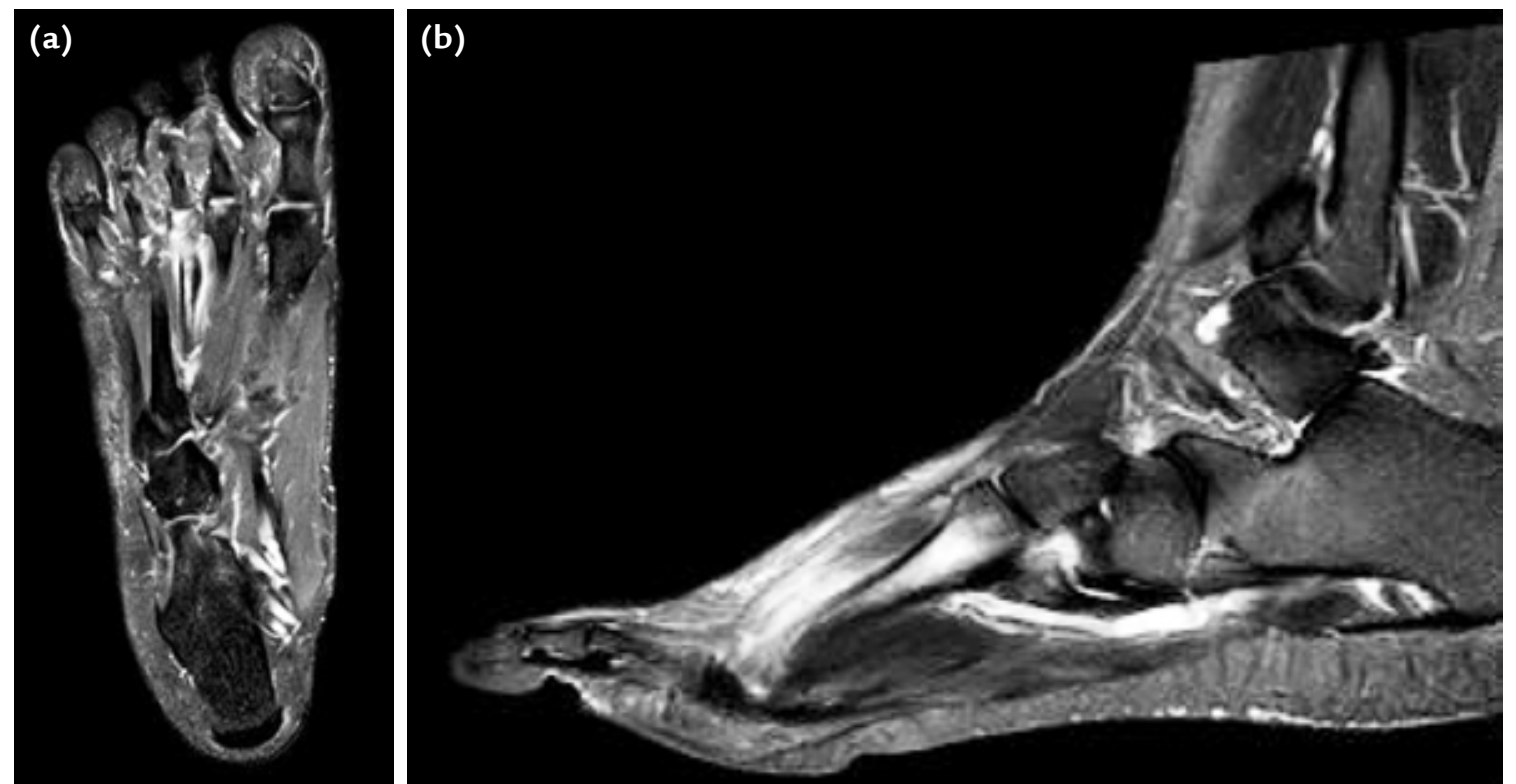

Şekil 4. a, b. Koşucu hastada 3. metatars stres kırı̆̆ı: aksiyel kesit (a); sagittal kesit (b).

Radyografi ilk üç haftaya kadar çoğunlukla bulgu vermez. Sintigrafi ve MR ileri tetkikler açısından çok yararlıdır ve özellikle MR ayırıcı tanıların değerlendirilmesi açısından daha değerlidir (Şekil 5).

Tedaviye öncelikle aktivite modifikasyonu ve yükten kesme ile başlanır. Genellikle 6-8 haftada spora dönüş sağlanır. Bazı hastalarda tedaviye, sert tabanlık, bantlama, yürüme botu veya nadiren yürüme alçısı eklenebilir.

\section{Kuneiform Stres Kırığı}

Kuneiform stres kırı̆gı ilk kez 1936 yılında askerlerde marş yürümesi sonrası ve medialde bildirilse de, sporcularda da görülmektedir. ${ }^{[19,20,72]}$ Zamanla lateral kuneifomda da bildirilmiştir. ${ }^{[20,73]}$ Radyografi ilk tanı aracı olsa da, MR daha tanı koydurucudur. Kemik iliği ile birlikte kırık hattı gözlenebilir. ${ }^{[72]}$ Ayak yük akslarından kaynaklanan kompresyon ve bending kuvvetleri ve 

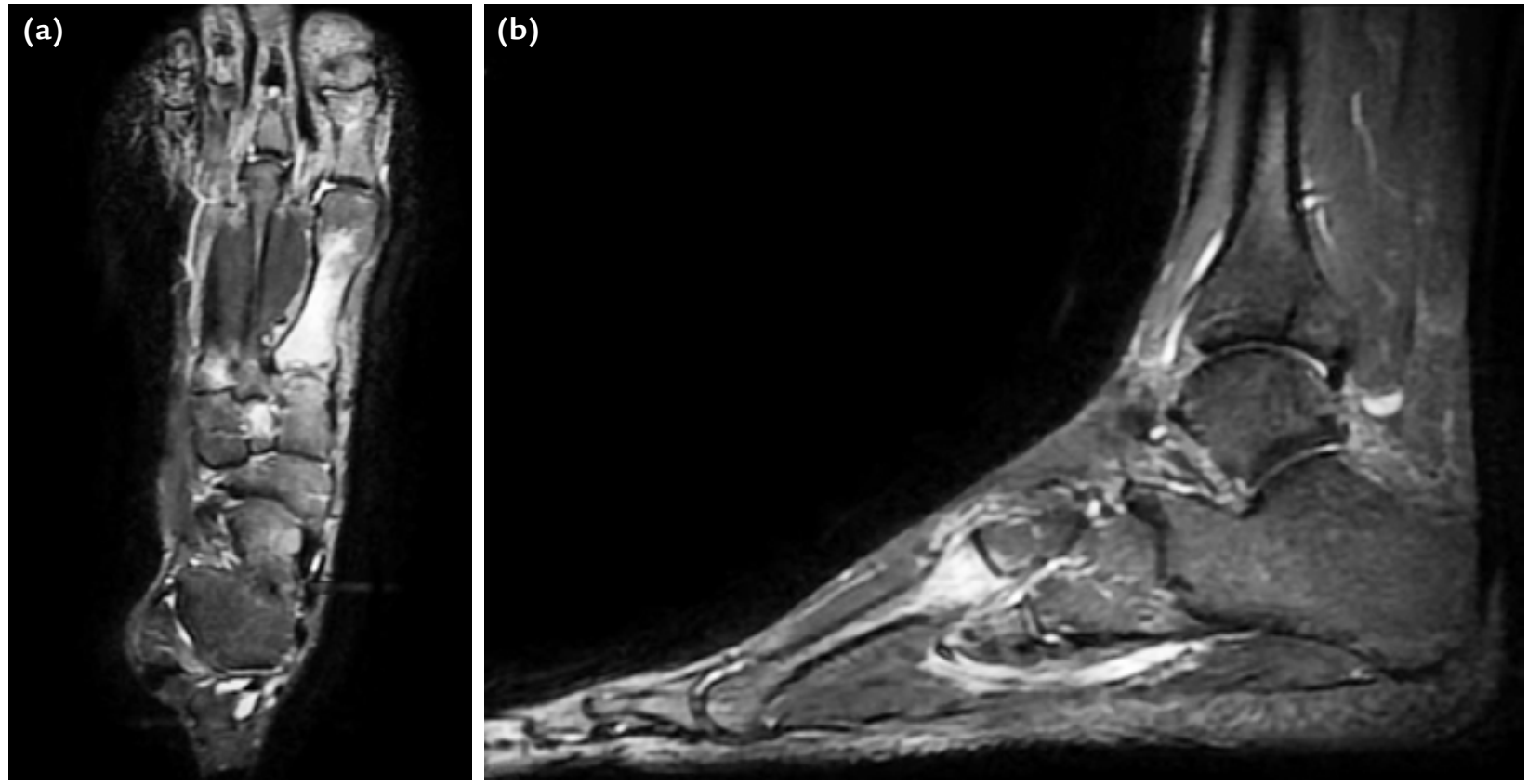

Şekil 5. a, b. Birinci metatars stres kırı̆̆ı: aksiyel kesit (a); sagittal kesit (b).

kas yapışmalarının yarattığı güçler kırık oluşumunda etkilidir. ${ }^{[19,20]}$

Sıklıkla cerrahi tedavi gerekmez. Illk altı hafta yükten keserek ya da kısmi yük vererek tedaviye başlanır ve ağrı tolere edilince spora dönmeye izin verilir.

\section{DIĞER TEDAVILER}

\section{Kalsiyum ve D vitamini}

Kemik döngüsü ve iyileşmesinde kalsiyum ve $D$ vitamininin büyük rolü olmasına rağmen, bunların stres kırıkları üzerine etkisi net olarak gösterilememiştir. ${ }^{[7,74,75]}$ Askerlerde ve yoğun antrenman dönemlerinde kemik döngüsü yüksek seviyelerde olmasına rağmen stres kırıkları da gözlenebilmektedir. ${ }^{[38,76,77]}$ Buradan yola çıkılarak çeşitli çalışmalar yapılmış ${ }^{[78,79]}$, McCabe ve ark. bu çalışmaları genel olarak değerlendirdiklerinde, stres kırığını önlemekle D vitamini arasında kesin bir ilişkinin varlığını gösterememişlerdir. ${ }^{\left[{ }^{[0]}\right.}$ Stres kırı̆̆ı ile kalsiyum ve $D$ vitamini arasında uyum olduğunu söyleyen çalışmalarda, kalsiyum ve $D$ vitamini miktarının yaş, cinsiyet ve antrenman yoğunluğuna bağlı olarak değiştiği, günlük 500-2000 mg kalsiyum ve 800-2000IU D vitamini desteğinin stres kırığını azaltacağı belirtilmiştir. ${ }^{[75,80-83]}$

\section{Kemik Uyaranları}

Kırık iyileşmesi üzerine elektromanyetik uyaranlar ve pulse ultrasonik uyaranların etkileri değerlendirilmiştir.
Elektromanyetik uyaranlar, kemik etrafinda manyetik bir alan oluşturur ve hücre membranında kalmodulini arttırarak kalsiyum kanallarını açar ve bu da hücre çoğalmasını arttırır. ${ }^{\left[{ }^{84]}\right.}$ Ultrasonografi ise vasküler endotelyal büyüme faktörü (VEGF) ve fibroblast büyüme faktörünü (FGF) arttırarak anjiyogenezisi uyarır ve kemik metabolizmasının aktivitesini gösteren ALP, kemik sialoprotein ve hücre içi kalsiyum artar. ${ }^{[85]}$ Her iki yöntem için de kırık iyileşmesi üzerine olumlu etkilerini gösteren çalışmalar mevcut ise de ${ }^{[86,87]}$, stres kırıkları üzerine olumlu etkileri üzerinde henüz fikir birliği yokturr ${ }^{[8]}$ ve yüksek seviyeli kontrollü çalışmalara ihtiyaç vardır.

\section{Bifosfonatlar}

Bifosfonatlar osteoklast aktivasyonunu ve kemik yıkımını inhibe ederek etki göstermekle birlikte, stres kırıklarında plasebo ile karşılaştırmalı yapılan çalışmalar sonucunda, stres kırığı üzerinde olumlu bir etkileri kanıtlanamamıştır. ${ }^{[89,90]}$

\section{ESWT}

Yüksek enerjili $\left(>0,2 \mathrm{~mJ} / \mathrm{mm}^{3}\right)$ ve düşük enerjili $\left(<0,2 \mathrm{~mJ} / \mathrm{mm}^{3}\right)$ akustik dalgalar şeklinde kullanılır ve etki ettikleri doku derinlikleri farklıdır. Dokular üzerinde yeniden damarlanma, büyüme faktörü salınımı ve osteojenik kök hücre uyaranı olarak etki ettiği söylenmektedir. ${ }^{[91]}$ Avasküler nekroz, kaynamama ve stres kırığı üzerine etkisi olduğu söylenen az olgulu 
seriler ${ }^{[92,93]}$ mevcut olsa da, etkinliğini net olarak gösterebilmek için daha yüksek seviyeli çalışmalara ihtiyaç vardır.

\section{Kalsitonin}

Osteoklastların inhibisyonu ile etkisini gösterir. Kemik mineralizasyonu ve biyomekanik özellikleri üzerine olumlu etkisi bilinse de, stres kırıklarında durdurucu ajan olarak kullanılmış, fakat tartışmalı sonuçlar bildirilmiştir. ${ }^{[94,95]}$

\section{Oral Kontraseptif (OKS)}

Yoğun antrenman programının ilk günlerinde düşük hormon seviyeleri gözlenir ve bu da kemik yoğunluğunda azalma ve ikincil amenore nedeni olarak gösterilmiştir. ${ }^{[96]}$ Özellikle koşucu ve kadın askerlerde yapılan bir çalışmada, amenore gelişenlerde OKS kullanımı ile yılda \%1'lik kemik mineralizasyonunda artış görülmesine karşın, stres kırı̆̆ına karşı koruyuculuk anlamında ciddi bir etkisi gözlenmemiştir. ${ }^{96-98]}$

\section{SONUÇ}

Ayak ve ayak bileği çevresi stres kırıkları, spor yaralanmalarında çok sık gözlenmemekle birlikte, bütün stres kırıklarının yaklaşık yarısını içerir. Genellikle sinsi başlangıçlı ağrı ile kendini gösterir. Üç haftaya kadar radyografik tetkikler genellikle tanı koydurmaz. Kemik sintigrafisi ve MR etkin yöntemler arasındadır ve özellikle MR, ayırıCı tanıların elenmesi açısından yararlıdır. Tedaviler çoğu zaman cerrahi dışı yöntemlerdir. Tedavinin süresi ve yöntemi, kırı̆ıın yeri ve türüne göre değişkenlik gösterebilir. Nadiren de olsa cerrahi tedavi uygulanması gerekebilir. Seçilecek tedavinin türü ve ek tedavi seçeneklerinin etkinliğinin değerlendirilmesi açısından, olgu serilerinden ziyade, yüksek kaliteli çalışmalara ihtiyaç vardır.

\section{KAYNAKLAR}

1. Hulkko A, Orava S. Stress fractures in athletes. Int J Sports Med 1987;8(3):221-6. Crossref

2. Boden BP, Osbahr DC. High-risk stress fractures: evaluation and treatment. J Am Acad Orthop Surg 2000;8(6):344-53.

3. Gehrmann RM, Renard RL. Current concepts review: stress fractures of the foot. Foot Ankle Int 2006;27(9):750-7.

4. Wentz L, Liu PY, Haymes E, Ilich JZ. Females have a greater incidence of stress fractures than males in both military and athletic populations: a systemic review. Mil Med 2011;176(4):420-30.

5. Hame SL, LaFemina JM, McAllister DR, Schaadt GW, Dorey FJ. Fractures in the collegiate athlete. Am J Sports Med 2004;32(2):446-51. Crossref

6. Matheson GO, Clement DB, McKenzie DC, Taunton JE, Lloyd-Smith DR, Macintyre JG. Stress fractures in athletes: a study of 320 cases. Am J Sports Med 1987;15(1):46-58. Crossref
7. Bennell KL, Malcolm SA, Thomas SA, Reid SJ, Brukner PD, Ebeling PR, Wark JD. Risk factors for stress fractures in track and field athletes. A twelve-month prospective study. Am J Sports Med 1996;24(6):810-8. Crossref

8. Boden BP, Osbahr DC, Jimenez C. Low-risk stress fractures. Am J Sports Med 2001;29(1):100-11. Crossref

9. Brukner P, Bradshaw C, Khan KM, White S, Crossley K. Stress fractures: a review of 180 cases. Clin J Sports Med 1996;6(2):85-9.

10. Changstrom BG, Brou L, Khodaee M, Braund C, Comstock RD. Epidemiology of stress fracture injuries among US high school athletes, 2005-2006 through 2012-2013. Am J Sports Med 2015;43(1):26-33. Crossref

11. Korpelainen R, Orava S, Karpakka J, Siira P, Hulkko A. Risk factors for recurrent stress fractures in athletes. Am J Sports Med 2001;29(3):304-10. Crossref

12. Maitra RS, Johnson DL. Stress fractures. Clinical history and physical examination. Clin Sports Med 1997;16(2):259-74.

13. Stanitski CL, McMaster JH, Scranton PE. On the nature of stress fractures. Am J Sports Med 1978;6(6):391-6. Crossref

14. Barrow GW, Saha S. Menstrual irregularity and stress fractures in collegiate female distance runners. Am J Sports Med 1988;16(3):209-16. Crossref

15. Voss LA, Fadale PD, Hulstyn MJ. Exercise-induced loss of bone density in athletes. J Am Acad Orthop Surg 1998;6(6):349-57.

16. Van Hal ME, Keene JS, Lange TA, Clancy WG Jr. Stress fractures of the great toe sesamoids. Am J Sports Med 1982;10(2):122-8. Crossref

17. Barrack MT, Gibbs JC, De Souza MJ, Williams NI, Nichols JF, Rauh MJ, Nattiv A. Higher incidence of bone stress injuries with increasing female athlete triad-related risk factors: a prospective multisite study of exercising girls and women. Am J Sports Med 2014;42(4):949-58. Crossref

18. Mallee $W H$, Weel $H$, van Dijk CN, van Tulder MW, Kerkhoffs GM, Lin CW. Surgical versus conservative treatment for highrisk stress fractures of the lower leg (anterior tibial cortex, navicular and fifth metatarsal base): a systematic review. $\mathrm{Br} J$ Sports Med 2015;49(6):370-6. Crossref

19. Meurman $\mathrm{KO}$. Less common stress fractures in the foot. $\mathrm{Br} \mathrm{J}$ Radiol 1981;54(637):1-7. Crossref

20. Meurman KO, Elfving $\mathrm{S}$. Stress fracture of the cuneiform bones. Br J Radiol 1980;53(626):157-60. Crossref

21. Shaffer RA, Rauh MJ, Brodine SK, Trone DW, Macera CA. Predictors of stress fractures in young female recruits. Am J Sports Med 2006;34(1):108-15. Crossref

22. Spitz DJ, Newberg $A H$. Imaging of stress fractures in the athlete. Radiol Clin North Am 2002;40(2):313-31.

23. Arendt EA, Griffiths HJ. The use of $M R$ imaging in the assessment and clinical management of stress reactions of bone in high-performance athletes. Clin Sports Med 1997;16(2):291-306.

24. Anderson MW, Greenspan A. Stress fractures. Radiology 1996;199(1):1-12. Crossref

25. Ziessman $\mathrm{H}$, O'Malley J, authors. Thrall J, editor. Nuclear medicine: The Requisites, 4th ed. St Louis (MO): Saunders; 2014.

26. Niva $M H$, Sormaala MJ, Kiuru MJ, Haataja R, Ahovuo JA, Pihlajamaki HK. Bone stress injuries of the ankle and foot: an 86-month magnetic resonance imaging-based study of physically active young adults. Am J Sports Med 2007;35(4):643-9. Crossref

27. Iwamoto J, Takeda T. Stress fractures in athletes: review of 196 cases. J Orthop Sci 2003;8(3):273-8. Crossref 
28. Shelbourne KD, Fisher DA, Rettig AC, McCarroll JR. Stress fractures of the medial malleolus. Am J Sports Med 1988;16(1):60-3. Crossref

29. Jowett AJ, Birks CL, Blackney MC. Medial malleolar stress fracture secondary to chronic ankle impingement. Foot Ankle Int 2008;29(7):716-21. Crossref

30. Shabat S, Smapson KB, Mann G, Gepstein R, Eliakim A, Shenkman Z, Nyska M. Stress fractures of the medial malleolus -review of the literature and report of a 15-year-old gymnast. Foot Ankle Int 2002;23(7):647-50. Crossref

31. Lempainen L, Liimatainen E, Heikkila J, Alonso J, Sarimo J, Mattila K, Orava S. Medial malleolar stress fracture in athletes: diagnosis and operative treatment. Scand J Surg 2012;101(4):261-4. Crossref

32. Orava S, Karpakka J, Taimela S, Hulkko A, Permi J, Kujala U. Stress fracture of the medial malleolus. J Bone Joint Surg Am 1995;77(3):362-5.

33. Kor A, Saltzman AT, Wempe PD. Medial malleolar stress fractures. Literature review, diagnosis, and treatment. J Am Podiatr Med Assoc 2003;93(4):292-7.

34. Irion V, Miller TL, Kaeding CC. The treatment and outcomes of medial malleolar stress fractures: a systematic review of the literature. Sports Health 2014;6(6):527-30. Crossref

35. Rossi F, Dragoni S. Talar body fatigue stress fractures: three cases observed in elite female gymnasts. Skeletal Radiol 2005;34(7):389-94. Crossref

36. Bradshaw C, Khan K, Brukner P. Stress fracture of the body of the talus in athletes demonstrated with computer tomography. Clin J Sports Med 1996;6(1):48-51.

37. Sormaala MJ, Niva MH, Kiuru MJ, Mattila VM, Pihlajamaki $\mathrm{HK}$. Bone stress injuries of the talus in military recruits. Bone 2006;39(1):199-204. Crossref

38. Evans RK, Antczak AJ, Lester M, Yanovich R, Israeli E, Moran DS. Effects of a 4-month recruit training program on markers of bone metabolism. Med Sci Sports Exerc 2008;40(11 Suppl):S660-70. Crossref

39. Black KP, Ehlert KJ. A stress fracture of the lateral process of the talus in a runner. A case report. J Bone Joint Surg Am 1994;76(3):441-3.

40. Motto SG. Stress fracture of the lateral process of the talus -a case report. Br J Sports Med 1993;27(4):275-6.

41. Torg JS, Pavlov H, Cooley LH, Bryant MH, Arnoczky SP, Bergfeld J, Hunter LY. Stress fractures of the tarsal navicular. A retrospective review of twenty-one cases. J Bone Joint Surg Am 1982;64(5):700-12.

42. Khan KM, Fuller PJ, Brukner PD, Kearney C, Burry HC. Outcome of conservative and surgical management of navicular stress fracture in athletes. Eighty-six cases proven with computerized tomography. Am J Sports Med 1992;20(6):657-66. Crossref

43. Leabhart JW. Stress fractures of the calcaneus. J Bone Joint Surg Am 1959;41-A:1285-90.

44. Fitch KD, Blackwell JB, Gilmour WN. Operation for nonunion of stress fracture of the tarsal navicular. J Bone Joint Surg Br 1989;71(1):105-10.

45. Khan KM, Brukner PD, Kearney C, Fuller PJ, Bradshaw CJ, Kiss ZS. Tarsal navicular stress fracture in athletes. Sports Med 1994;17(1):65-76.

46. Burne SG, Mahoney CM, Forster BB, Koehle MS, Taunton JE, Khan KM. Tarsal navicular stress injury: long-term outcome and clinicoradiologic correlation using both computed tomography and magnetic resonance imaging. Am J Sports Med 2005;33(12):1875-81. Crossref
47. Finestone $A$, Giladi $M$, Elad $H$, Salmon $A$, Mendelson $S$, Eldad A, Milgrom C. Prevention of stress fractures using custom biomechanical shoe orthoses. Clin Orthop Relat Res 1999;(360):182-90.

48. Saxena A, Fullem B, Hannaford D. Results of treatment of 22 navicular stress fractures and a new proposed radiographic classification system. J Foot Ankle Surg 2000;39(2):96-103.

49. Saxena A, Fullem B. Navicular stress fractures: a prospective study on athletes. Foot Ankle Int 2006;27(11):917-21. Crossref

50. Torg JS, Moyer J, Gaughan JP, Boden BP. Management of tarsal navicular stress fractures: conservative versus surgical treatment: a meta-analysis. Am J Sports Med 2010;38(5):1048-53. Crossref

51. Lee $S$, Anderson RB. Stress fractures of the tarsal navicular. Foot Ankle Clin 2004;9(1):85-104. Crossref

52. Gross CE, Nunley JA 2nd. Navicular Stress Fractures. Foot Ankle Int 2015;36(9):1117-22. Crossref

53. DeLee JC, Evans JP, Julian J. Stress fracture of the fifth metatarsal. Am J Sports Med 1983;11(5):349-53. Crossref

54. Kavanaugh JH, Brower TD, Mann RV. The Jones fracture revisited. J Bone Joint Surg Am 1978;60(6):776-82.

55. Hetsroni I, Nyska M, Ben-Sira D, Mann G, Segal O, Maoz $\mathrm{G}$, Ayalon M. Analysis of foot structure in athletes sustaining proximal fifth metatarsal stress fracture. Foot Ankle Int 2010;31(3):203-11. Crossref

56. Lee KT, Kim KC, Park YU, Kim TW, Lee YK. Radiographic evaluation of foot structure following fifth metatarsal stress fracture. Foot Ankle Int 2011;32(8):796-801. Crossref

57. Torg JS, Balduini FC, Zelko RR, Pavlov H, Peff TC, Das M. Fractures of the base of the fifth metatarsal distal to the tuberosity. Classification and guidelines for nonsurgical and surgical management. J Bone Joint Surg Am 1984;66(2):209-14

58. Zogby RG, Baker BE. A review of nonoperative treatment of Jones' fracture. Am J Sports Med 1987;15(4):304-7. Crossref

59. Porter DA, Duncan M, Meyer SJ. Fifth metatarsal Jones fracture fixation with a $45-\mathrm{mm}$ cannulated stainless steel screw in the competitive and recreational athlete: a clinical and radiographic evaluation. Am J Sports Med 2005;33(5):72633. Crossref

60. Lee KT, Park YU, Young KW, Kim JS, Kim JB. Surgical results of 5th metatarsal stress fracture using modified tension band wiring. Knee Surg Sports Traumatol Arthrosc 2011;19(5):853-7. Crossref

61. Lee KT, Park YU, Young KW, Kim JS, Kim JB. The plantar gap: another prognostic factor for fifth metatarsal stress fracture. Am J Sports Med 2011;39:2206-11. Crossref

62. Biedert R, Hintermann B. Stress fractures of the medial great toe sesamoids in athletes. Foot Ankle Int 2003;24(2):137-41. Crossref

63. Brockwell J, Yeung Y, Griffith JF. Stress fractures of the foot and ankle. Sports Med Arthrosc Rev 2009;17(3):149-59. Crossref

64. Pagenstert Gl, Valderrabano V, Hintermann B. Medial sesamoid nonunion combined with hallux valgus in athletes: a report of two cases. Foot Ankle Int 2006;27(2):135-40. Crossref

65. Anderson RB, McBryde AM Jr. Autogenous bone grafting of hallux sesamoid nonunions. Foot Ankle Int 1997;18(5):2936. Crossref 
66. Saxena A, Krisdakumtorn T. Return to activity after sesamoidectomy in athletically active individuals. Foot Ankle Int 2003;24(5):415-9. Crossref

67. Devas MB, Sweetnam R. Stress fractures of the fibula; a review of fifty cases in athletes. J Bone Joint Surg $\mathrm{Br}$ 1956;38-B(4):818-29.

68. Takebe K, Nakagawa A, Minami H, Kanazawa H, Hirohata $\mathrm{K}$. Role of the fibula in weight-bearing. Clin Orthop Relat Res 1984;(184):289-92.

69. Hullinger CW. Insufficiency fractures of the calcaneus. J Bone Joint Surg 1944;26:751-7.

70. Sormaala MJ, Niva MH, Kiuru MJ, Mattila VM, Pihlajamaki HK. Stress injuries of the calcaneus detected with magnetic resonance imaging in military recruits. J Bone Joint Surg Am 2006;88(10):2237-42. Crossref

71. Albisetti W, Perugia D, De Bartolomeo O, Tagliabue L, Camerucci E, Calori GM. Stress fractures of the base of the metatarsal bones in young trainee ballet dancers. Int Orthop 2010;34(1):51-5. Crossref

72. Bui-Mansfield LT, Thomas WR. Magnetic resonance imaging of stress injury of the cuneiform bones in patients with plantar fasciitis. J Comput Assist Tomogr 2009;33(4):593-6. Crossref

73. Childress HM. March fractures of the lower extremity. Report of a case of March fracture of a cuneiform bone. War Medicine 1943;4:152-60.

74. Cline AD, Jansen GR, Melby CL. Stress fractures in female army recruits: implications of bone density, calcium intake, and exercise. J Am Coll Nutr 1998;17(2):128-35.

75. Lappe J, Cullen D, Haynatzki G, Recker R, Ahlf R, Thompson $K$. Calcium and vitamin D supplementation decreases incidence of stress fractures in female navy recruits. J Bone Miner Res 2008;23(5):741-9. Crossref

76. Friedl KE, Evans RK, Moran DS. Stress fracture and military medical readiness: bridging basic and applied research. Med Sci Sports Exerc 2008;40(11 Suppl):S609-22. Crossref

77. Jones BH, Thacker SB, Gilchrist J, Kimsey CD Jr, Sosin DM. Prevention of lower extremity stress fractures in athletes and soldiers: a systematic review. Epidemiol Rev 2002;24(2):228-47.

78. Tangpricha V, Pearce EN, Chen TC, Holick MF. Vitamin D insufficiency among free-living healthy young adults. Am J Med 2002;112(8):659-62.

79. Constantini NW, Arieli R, Chodick G, Dubnov-Raz G. High prevalence of vitamin $\mathrm{D}$ insufficiency in athletes and dancers. Clin J Sport Med 2010;20(5):368-71. Crossref

80. McCabe MP, Smyth MP, Richardson DR. Current concept review: vitamin $D$ and stress fractures. Foot Ankle Int 2012;33(6):526-33. Crossref

81. Nieves JW, Melsop K, Curtis M, Kelsey JL, Bachrach LK, Greendale G, Sowers MF, Sainani KL. Nutritional factors that influence change in bone density and stress fracture risk among young female cross-country runners. PM R 2010;2(8):740-50. Crossref

82. Bischoff-Ferrari HA, Willett WC, Wong JB, Giovannucci E, Dietrich T, Dawson-Hughes B. Fracture prevention with vitamin D supplementation: a meta-analysis of randomized controlled trials. JAMA 2005;293(18):2257-64. Crossref

83. National Institutes of Health Office of Dietary Supplements. Dietary supplement fact sheet vitamin D. http://ods.od.nih. gov/factsheets/VitaminD-HealthProfessional/ Accessed: May 4, 2018.
84. Brighton CT, Wang W, Seldes R, Zhang G, Pollack SR. Signal transduction in electrically stimulated bone cells. J Bone Joint Surg Am 2001;83-A(10):1514-23.

85. Khan $\mathrm{Y}$, Laurencin CT. Fracture repair with ultrasound: clinical and cell- based evaluation. J Bone Joint Surg Am 2008;90 Suppl 1:S138-44. Crossref

86. Beck BR, Matheson GO, Bergman G, Norling T, Fredericson M, Hoffman AR, Marcus R. Do capacitively coupled electric fields accelerate tibial stress fracture healing? A randomized controlled trial. Am J Sports Med 2008;36(3):545-53. Crossref

87. Busse JW, Kaur J, Mollon B, Bhandari M, Tornetta $P$, Schünemann $H J$ Guyatt GH. Low intensity pulsed ultrasonography for fractures: systematic review of randomized controlled trials. BMJ 2009;338:b351. Crossref

88. Needle AR, Kaminski TW. Effectiveness of low-intensity pulsed ultrasound, capacitively coupled electric fields, or extracorporeal shock wave therapy in accelerating stress fracture healing: a systematic review. Athl Train Sports Health Care 2009;1(3):133-9. Crossref

89. Barrett JG, Sample SJ, McCarthy J, Kalsheur VL, Muir P, Prokuski L. Effect of short-term treatment with alendronate on ulnar bone adaptation to cyclic fatigue loading in rats. J Orthop Res 2007;25(8):1070-7. Crossref

90. Milgrom C, Finestone A, Novack V, Pereg D, Goldich Y, Kreiss Y, Zimlichman E, Kaufman S, Liebergall M, Burr D. The effect of prophylactic treatment with risedronate on stress fracture incidence among infantry recruits. Bone 2004;35(2):418-24. Crossref

91. Furia JP, Rompe JD, Cacchio A, Maffulli N. Shock wave therapy as a treatment of nonunions, avascular necrosis, and delayed healing of stress fractures. Foot Ankle Clin 2010;15(4):651-62. Crossref

92. Moretti B, Notarnicola A, Garofalo R, Moretti L, Patella S, Marlinghaus E, Patella V. Shock waves in the treatment of stress fractures. Ultrasound Med Biol 2009;35(6):1042-9. Crossref

93. Taki $M$, Iwata $O$, Shiono $M$, Kimura $M$, Takagishi $K$. Extracorporeal shock wave therapy for resistant stress fracture in athletes: a report of 5 cases. Am J Sports Med 2007;35(7):1188-92. Crossref

94. Li X, Luo X, Yu N, Zeng B. Effects of salmon calcitonin on fracture healing in ovariectomized rats. Saudi Med J 2005;28(1):60-4.

95. Manabe T, Mori S, Mashiba T, Cao Y, Kaji Y, Iwata K, Komatsubara S, Yamamoto T, Seki A, Norimatsu H. Eel calcitonin (elcatonin) suppressed callus remodeling but did not interfere with fracture healing in the femoral fracture model of cynomolgus monkeys. J Bone Miner Metab 2009;27(3):295-302. Crossref

96. Cumming DC, Cumming CE. Estrogen therapy and female athletes: current issues. Sports Med 2001;31(15):1025-31.

97. Cobb KL, Bachrach LK, Sowers M, Nieves J, Greendale GA, Kent KK, Brown BW Jr, Pettit K, Harper DM, Kelsey JL. The effect of oral contraceptives on bone mass and stress fractures in female runners. Med Sci Sports Exerc 2007;39(9):146473. Crossref

98. Cumming DC. Exercise-induced amenorrhea, low bone density, and estrogen replacement therapy. Arch Intern Med 1996;156(19):2193-5. 